\title{
Correction to: Non-tropical Cyclone Related Winter Heavy Rainfall Events over the Philippines: Climatology and Mechanisms
}

\author{
Lyndon Mark Olaguera $^{1,2}$ (D) Jun Matsumoto ${ }^{1,3} \cdot$ Julie Mae B. Dado ${ }^{2} \cdot$ Gemma Teresa T. Narisma $^{2,4}$
}

Published online: 27 February 2020

(C) The Author(s) 2020

\section{Correction to: Asia-Pacific J Atmos Sci https://doi.org/10.1007/s13143-019-00165-2}

The article "Non-tropical Cyclone Related Winter Heavy Rainfall Events over the Philippines: Climatology and Mechanisms", written by Lyndon Mark Olaguera, Jun Matsumoto, Julie Mae B. Dado and Gemma Teresa T. Narisma, was originally published electronically on the publisher's internet portal on 02 January 2020 without open access. With the author(s)' decision to opt for Open Choice the copyright of the article changed on 26 February 2020 to (C) The Author(s) 2020 and the article is forthwith distributed under a Creative Commons Attribution 4.0 International License (https://creativecommons.org/licenses/by/4.0/), which permits use, sharing, adaptation, distribution and reproduction in any medium or format, as long as you give appropriate credit to the original author(s) and the source, provide a link to the Creative Commons licence, and indicate if changes were made.

Also, the original version of this article unfortunately contained some mistakes. Due to a typesetting error, Fig. 11 contained wrong symbols for the vorticity tendency, and a wrong version of Fig. 12 had been included in the article. The correct figures are shown below. The publisher apologizes for any inconvenience caused by the typesetting mistakes.

The original article has been corrected.

Publisher's Note Springer Nature remains neutral with regard to jurisdictional claims in published maps and institutional affiliations.

Open Access This article is licensed under a Creative Commons Attribution 4.0 International License, which permits use, sharing, adaptation, distribution and reproduction in any medium or format, as long as you give appropriate credit to the original author(s) and the source, provide a link to the Creative Commons licence, and indicate if changes were made. The images or other third party material in this article are included in the article's Creative Commons licence, unless indicated otherwise in a credit line to the material. If material is not included in the article's Creative Commons licence and your intended use is not permitted by statutory regulation or exceeds the permitted use, you will need to obtain permission directly from the copyright holder. To view a copy of this licence, visit http://creativecommons.org/licenses/by/4.0/.

The online version of the original article can be found at https://doi.org/ 10.1007/s13143-019-00165-2

Lyndon Mark Olaguera

lyndonmarkolaguera@ed.tmu.ac.jp; lmolaguera@ observatory.ph

Jun Matsumoto

jun@tmu.ac.jp

Julie Mae B. Dado

jmbdado@observatory.ph

Gemma Teresa T. Narisma

gnarisma@ateneo.edu
1 Department of Geography, Tokyo Metropolitan University, 1-1 Minami-Osawa, Hachioji-Shi, Tokyo 192-0397, Japan

2 Present address: Regional Climate Systems Laboratory, Manila Observatory, Ateneo de Manila University Campus, Loyola Heights, 1108 Quezon City, Philippines

3 Dynamic Coupling of Ocean-Atmosphere-Land Research Program, Japan Agency for Marine Earth Science and Technology, Yokosuka, Kanagawa 237-0061, Japan

4 Physics Department, Ateneo de Manila University, Loyola Heights, 1108 Quezon City, Philippines 
(a) $\operatorname{Lag}-3 \zeta_{t}$

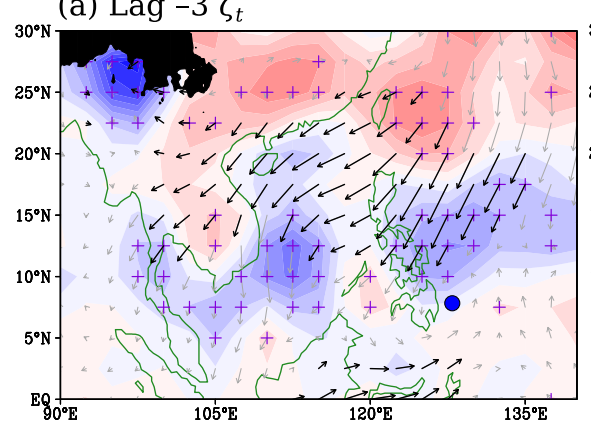

(d) Lag $0 \zeta_{t}$

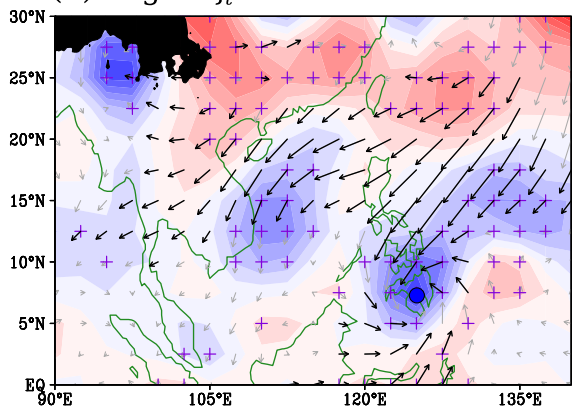

(g) $\operatorname{Lag}+1 \zeta_{t}$

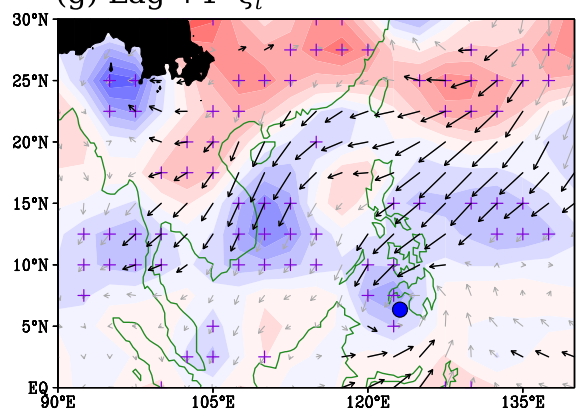

(b) $\operatorname{Lag}-3 \zeta_{a d v}$

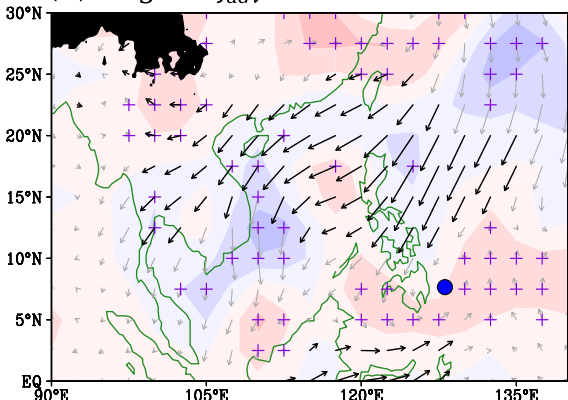

(e) Lag $0 \zeta_{a d v}$

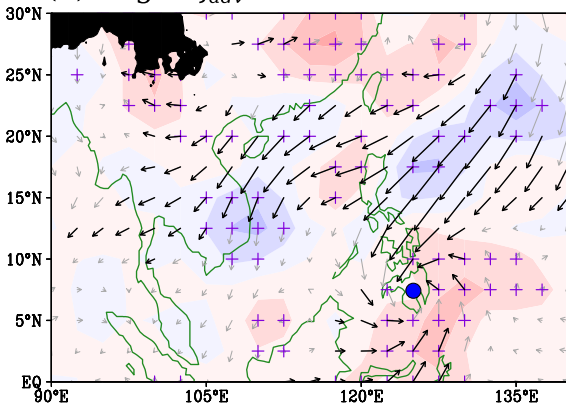

(h) $\operatorname{Lag}+1 \zeta_{a d v}$

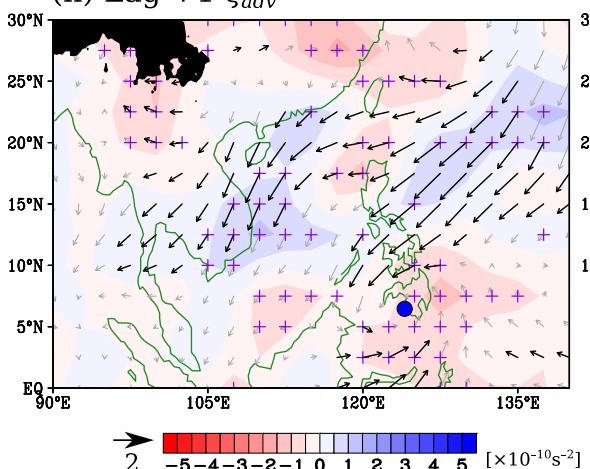

(c) Lag $-3 \zeta_{\text {stretch }}$

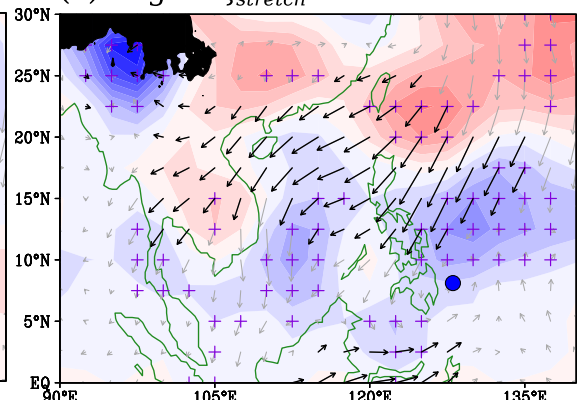

(f) Lag $0 \zeta_{\text {stretch }}$

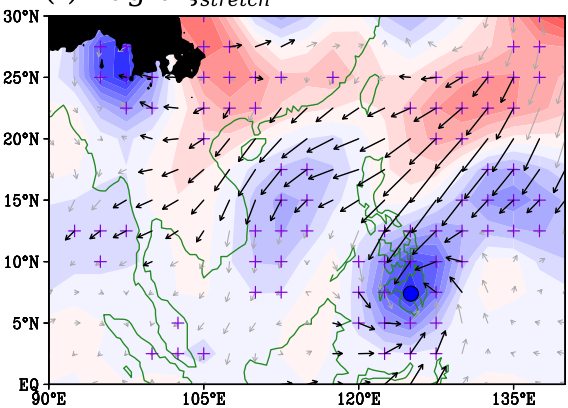

(i) Lag $+1 \zeta_{\text {stretch }}$

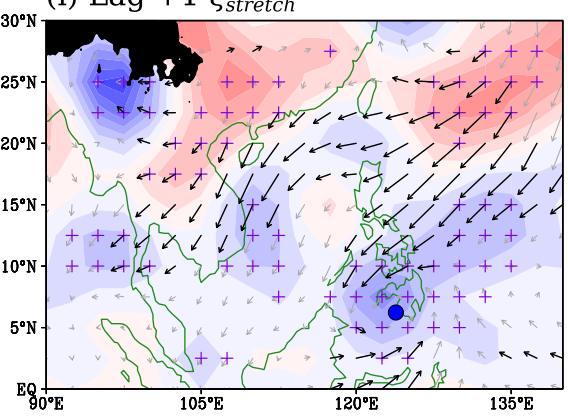

Fig. 11 Spatial distribution of composite anomalies of vorticity tendency $\left(\zeta_{\mathrm{t}} ; \times 10^{-10} \mathrm{~s}^{-2}\right)$, its advection term $\left(\zeta_{\mathrm{adv}} ; \times 10^{-10} \mathrm{~s}^{-2}\right)$, and stretching term $\left(\zeta_{\text {stretch }} ; \times 10^{-10} \mathrm{~s}^{-2}\right)$ for: Lag $-3(\mathrm{a}, \mathrm{b}, \mathrm{c})$; Lag 0 (d, e, f); and Lag +1 (g, h, i), respectively. The $925 \mathrm{hPa}$ wind anomalies $\left(\mathrm{m} \mathrm{s}^{-1}\right)$ are superimposed for discussion. The blue circle indicates the center of the anomalous cyclonic circulation over Mindanao Island (MCC). Bold vectors and cross markings (+) indicate statistical significance at the $90 \%$ confidence level using Student's $t$ test. The scale of the wind vector is $2 \mathrm{~m} \mathrm{~s}^{-1}$ 


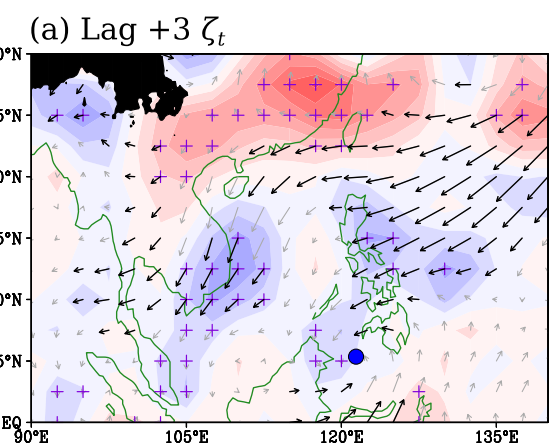

(d) $\operatorname{Lag}+5 \zeta_{t}$

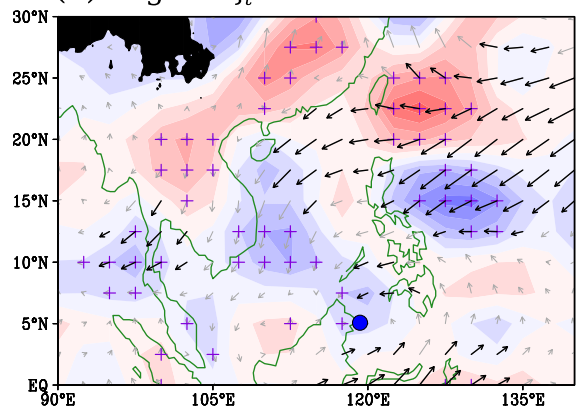

(b) $\mathrm{Lag}+3 \zeta_{a d v}$

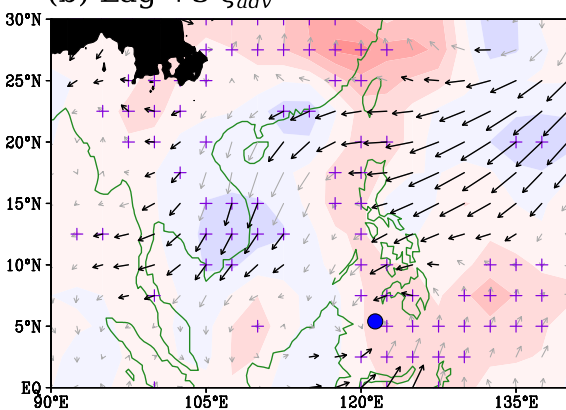

(e) $\operatorname{Lag}+5 \zeta_{a d v}$

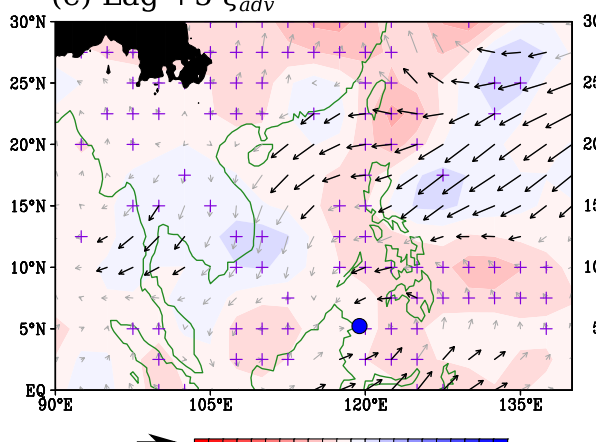

(c) Lag $+3 \zeta_{\text {stretch }}$

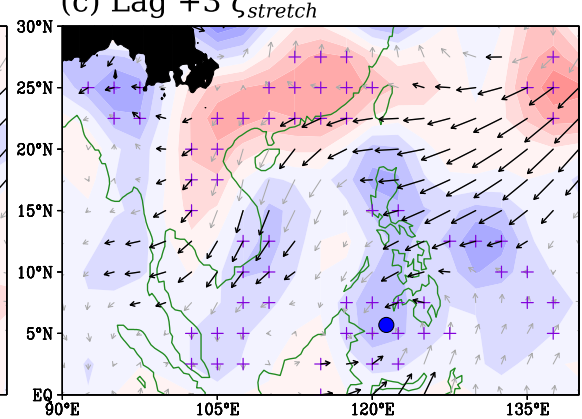

(f) $\mathrm{Lag}+5 \zeta_{\text {stretch }}$

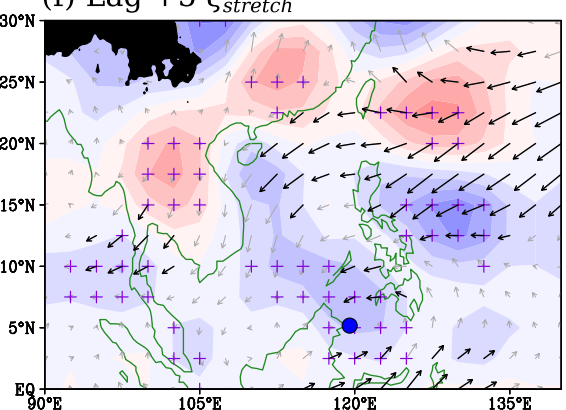

Fig. 12 As in Fig. 11 but for: $\operatorname{Lag}+3(a, b, c)$; and $\operatorname{Lag}+5$ (d, e, f) 